\title{
DESCUBRIMIENTO E IMPLEMENTACIÓN DEL PÁJARO CARPINTERO GIGANTE (CAMPEPHILUS MAGELLANICUS) COMO ESPECIE CARISMÁTICA: UNA APROXIMACIÓN BIOCULTURAL PARA LA CONSERVACIÓN EN LA RESERVA DE BIOSFERA CABO DE HORNOS
}

\author{
XIMENA ARANGO", RICARDO ROZZI"/"*, FRANCISCA MASSARDO", \\ CHRISTOPHER B. ANDERSON* Y TOMÁS IBARRA"***
}

\begin{abstract}
RESUMEN
Al sur de Sudamérica se encuentra la Reserva de Biosfera Cabo de Hornos donde persisten los bosques siempreverdes subantárticos. Esta zona, considerada una de las más prístinas del mundo, está sometida a presiones crecientes de conectividad, crecimiento urbano y desarrollo turístico, sin embargo, todavía alberga bosques no fragmentados de Nothofagus. Con una aproximación biocultural a la conservación determinamos que el pájaro carpintero gigante (Campephilus magellanicus) es la especie de ave preferida por la comunidad de Puerto Williams, capital de la Provincia Antártica Chilena, ciudad más austral del mundo y mayor asentamiento humano de la reserva. Aunque existen diferencias significativas $(\mathrm{P}<0.05)$ en las preferencias hacia las aves por parte de los distintos grupos socioculturales entrevistados todos coincidieron en sus preferencias hacia el carpintero Gigante. Esta especie de ave fue la predilecta para las personas que llevan más tiempo en el Cabo de Hornos: los miembros de la Comunidad Indígena Yagán y los residentes más antiguos. El análisis de estos resultados, así como el descubrimiento de diez atributos que presenta esta especie de pícido que además es el más grande de Sudamérica, nos han llevado a considerarlo como una especie carismática o emblemática con un alto potencial para la conservación de los bosques australes de la Reserva de Biosfera Cabo de Hornos. Por las anteriores razones el carpintero gigante puede transformarse en un símbolo o especie carismática para la conservación de los prístinos bosques australes. Entre el año 2005 y 2007 desarrollamos el Programa para la Implementación del Carpintero Gigante con el objetivo de aumentar su valoración y la de su hábitat y el conocimiento por parte de la comunidad local. El descubrimiento del potencial de esta especie como carismática así como su posterior implementación podrían contribuir a la conservación de los frágiles, singulares y bellos bosques australes y su diversidad biológica y cultural sin igual.
\end{abstract}

PALABRAS CLAVES: Campephilus magellanicus, especie carismática, conservación, bosques antiguos, Reserva de Biosfera Cabo de Hornos.

* Parque Etnobotánico Omora, Universidad de Magallanes - Sede Puerto Williams e Instituto de Ecología y Biodiversidad (IEB-Chile) Correo electrónico: xae_arango@yahoo.es

* Department of Philosophy and Religion Studies, University of North Texas, Denton, USA

*** Laboratorio Fauna Australis, Programa de Recursos Naturales, Facultad de Agronomía e Ingeniería Forestal, Pontificia Universidad Católica de Chile 


\title{
DISCOVERY AND IMPLEMENTATION OF MAGELLANIC WOODPECKER (CAMPEPHILUS MAGELLANICUS) AS AN EMBLEMATIC SPECIES: A BIOCULTURAL APPROACH FOR CONSERVATION IN CAPE HORN BIOSPHERE RESERVE
}

\begin{abstract}
At the southernmost part of South America there is Cape Horn Biosphere Reserve where the Magellanic sub-Antarctic evergreen unfragmented the Nothofagus forests still persist. This zone has been considered as one of the world's most pristine regions and this area is currently subject to increasing development pressures from new connectivity, urban expansion and tourism development. Using a biocultural approach we found that the Magellanic Woodpecker (Campephilus magellanicus) is the favorite bird for the community of Puerto Williams, the world's southernmost town and the biggest human centre in the Cape Horn Biosphere Reserve. Although, significant differences $(\mathrm{P}<0,05)$ exists between the preferences of the sociocultural groups toward birds, all groups agreed in their preferences toward the Magellanic woodpecker. This species of bird was the preferred for the people who have been longer in Cape Horn: the members of the Yahgan Indigenous Community and long time residents. The analysis of these results as well as the discovery of ten attributes that this species of picid presents which in addition is the largest of South America, have taken us to consider it like a charismatic or emblematic species with a high potential for the conservation of the austral forests of Cape Horn Biosphere Reserve. For this previous reasons the Magellanic woodpecker could be transformed into a symbol or a charismatic species for the conservation of the pristine austral forest. Between the year 2005 and 2007 we developed the Magellanic Woodpecker Implementation Program with the objective to increase both its intrinsic value and habitat valuation and the knowledge from the local community. The discovery of this species potential as well as their later implementation may contribute to the conservation of the fragile, singular and beautiful austral forests and its singular biological and cultural diversity.
\end{abstract}

KEY WORDS: Campephilus magellanicus, charismatic species, conservation, old-growth forests, Cape Horn Bisophere Reserve.

\section{INTRODUCCIÓN}

Los bosques siempreverdes y deciduos de Nothofagus en el extremo sur de Sudamérica conforman los bosques más australes del planeta (Rozzi et al. 2006, Rozzi et al. 2006a). La ecorregión de los bosques subantárticos de Magallanes en el extremo austral es, además, una de las escasas áreas del mundo donde aún se conservan bosques templados no fragmentados y sin impacto humano directo (Silander 2000; Mittermeir et al. 2002; Rozzi et al. 2004). Esta fue una de las razones para la creación de la Reserva de Biosfera Cabo de Hornos nominada por la UNESCO en junio del año 2005. Con un total de 4.884.274 ha (2.967.036 ha de zonas marinas y 1.917.238 ha de zonas terrestres), es la mayor reserva de biosfera de Chile y del Cono Sur de Sudamérica (Uruguay, Argentina y Chile) (Rozzi et al. 2006a). Dentro de este territorio insular, predomina un mosaico de tundra y bosques dominados por especies del género Nothofagus que se combinan formando distintos tipos de ecosistemas forestales: bosques lluviosos siempreverdes sub-polares de Magallanes dominados por coigüe de Magallanes (Nothofagus betuloides) en los sectores insulares del borde Pacífico, bosques subantárticos deciduos de nirre ( $N$. antarctica) en sectores altos y perhúmedos, bosques deciduos de lenga ( $N$. pumilio) en laderas con buen drenaje, y bosques mixtos de lenga y coigüe de Magallanes en sectores bajos de las islas que bordean el canal Beagle (Pisano 1977; Rozzi et al. 2006a).

Una vez creada la Reserva de Biosfera Cabo de Hornos, la tarea propuesta por el Gobierno de Chile es implementarla a través del desarrollo de actividades económicas sustentables, protegiendo y conservando a la vez estos ecosistemas naturales únicos en el mundo. El hecho que estos ecosistemas se conserven en estado casi prístino ofrece un gran potencial económico para el desarrollo ecoturístico (Martinic 2006; Rozzi et al. 2004). Sin embargo, el atractivo del potencial económico podría fácilmente conducir a un desarrollo económico cortoplacista, con turismo poco regulado y de alto impacto ambiental y social negativo en la región archipelágica austral (Martinic 2006; Rozzi et al. 2006). Si se quiere conservar estos bosques así como su diversidad biológica y cultural, es necesario desarrollar acciones de conservación con la participación de las comunidades locales y regionales. Una forma 
de contribuir a la orientación de tales acciones es a través de la definición de una especie carismática o emblemática que sirva como símbolo para valorar la biodiversidad de una región, y que pueda convertirse en un estímulo para la integración de motivaciones ecológicas y socioculturales (Dietz et al. 1994; Walpole y Leader-Williams 2002).

En este trabajo presentamos la investigación que identificó al pájaro carpintero negro (carpintero negro o carpintero gigante, Campephilus magellanicus) como una especie carismática o emblemática para la Reserva de Biosfera Cabo de Hornos. Nuestra aproximación considera la metodología utilizada para su identificación y la metodología utilizada para su posterior implementación a nivel local y regional.

\section{ESPECIE CARISMÁTICA}

El término especie carismática se ocupó por primera vez a mediados de los años ochenta (Mittermeier 1986; Walpole y Leader-Williams 2002) y alude a una especie popular que sirve como símbolo y estimula la conciencia pública hacia la importancia de conservar la biodiversidad (Heywood 1995) y puede llegar a liderar una campaña de conservación (Simberloff 1998). A nivel mundial, la elección de especies carismáticas ha estado basada en criterios estéticos y/o su estado de conservación (Kleiman et al. 1987; Dietz et al. 1994). Ejemplos exitosos de la implementación del concepto de especie carismática es el programa para la recuperación del mono tití dorado (Leonthopitecus rosalia) amenazado en Brasil (Kleiman et al. 1987; Dietz et al. 1994; Leader-Williams y Dublin 2001) y el programa para conservar al oso panda gigante (Ailuropoda melanoleuca). El oso panda fue adoptado como símbolo o especie emblemática del Fondo Mundial para la Naturaleza (World Wild Fund for Nature, WWF) porque captura la atención de millones de personas y ha contribuido a conseguir apoyo financiero para su conservación y la de su hábitat (Dietz et al. 1994).

Por lo general las especies carismáticas incluyen aves (como el cóndor) y mamíferos llamativos (grandes felinos o primates). Sólo muy ocasionalmente algunas plantas (como orquídeas o cactus) o invertebrados (mariposas y pequeños insectos) han cumplido esta función (Heywood 1995; Meffe y Carroll 1997). Respecto al ecoturismo e ingreso económico potencial, en un elevado número de áreas protegidas se ha registrado que las aves apoyan en mayor grado un turismo sustentable (Krüger 2005). Los turistas pagan grandes sumas de dinero para visitar zonas que contengan aves atractivas (Naidoo y Adamowicz 2005), especialmente si se trata de especies reconocidas como carismáticas (Walpole y Leader-Williams 2002).

En la Reserva de Biosfera Cabo de Hornos las aves constituyen el grupo de vertebrados más diverso, con más de 90 especies de aves marinas y terrestres (Couve y Vidal 2003). Otros grupos de vertebrados terrestres, como anfibios y reptiles, no están presentes en el área debido a las bajas temperaturas del extremo austral, y los mamíferos terrestres-costeros presentan solamente 9 especies (Anderson et al. 2006; Rozzi et al. 2006a). Además, en la región del Cabo de Hornos las aves se distribuyen en todos los tipos de hábitats, aspecto relevante puesto que si protegemos las especies carismáticas entonces también se preservará su hábitat y un número significativo de otras especies y procesos naturales in situ (Primack y Massardo 2001).

Es así que para nuestro estudio en la Reserva de Biosfera Cabo de Hornos decidimos centrar nuestra atención en la búsqueda de una especie carismática dentro del grupo de aves, y su posterior implementación para la conservación de los bosques antiguos. Un aspecto fundamental e innovador que debemos destacar en este trabajo es que utilizamos metodologías que nos permitieron identificar una especie carismática desde la percepción de la comunidad local, y no únicamente a partir de criterios estéticos o ecológicos definidos a priori. Es decir, aunque se decidió centrar la búsqueda en el grupo taxonómico o clase de las aves, a nivel de especie la identificación del ave fue a posteriori basado en el resultado de las encuestas.

Los objetivos específicos de esta investigación fueron: 1) identificar las especies de aves preferidas por la comunidad de Puerto Williams; 2) determinar aquellas con mayor potencial para actuar como una especie carismática; 3) identificar los atributos o criterios para nominar una especie como carismática para la conservación de los ecosistemas de la Reserva de Biosfera Cabo de Hornos; y 4) diseñar y aplicar acciones de educación y de difusión local y regional, enfocadas hacia la conservación de la especie carismática y de su hábitat al proponerla 
como especie carismática de la Reserva de Biosfera Cabo de Hornos a través de la implementación de un proceso de socialización.

\section{MATERIALES Y MÉTODOS}

Área de Estudio

Este trabajo se realizó con la población de la ciudad de Puerto Williams (545'ㅇ' 67³6'O), capital de la Provincia Antártica Chilena y mayor asentamiento humano de la Reserva de Biosfera Cabo de Hornos, con 2.262 habitantes (INE 2002 en Rozzi et al. 2006a). La ciudad está ubicada en la costa norte de la isla Navarino y los hábitats incluyen bosques siempreverdes de coigüe de Magallanes, bosques mixtos de coigüe y lenga, diversas formaciones de tundra, zonas altoandinas, y algunas áreas de matorral y praderas antrópicas en los sistemas terrestres. En los sistemas marinos están incluidas costas de bolones, costas rocosas, formaciones de bahías, sistemas de fiordos y canales, y algunas zonas más expuestas (Rozzi et al. 2006a).

Identificación del conocimiento y

preferencia por especies de aves

El estudio de los parámetros que nos permitieron identificar las especies de aves carismáticas potenciales se realizó a través de encuestas aplicadas a la población de Puerto Williams. La población está conformada por diversos grupos socio-culturales. Entre ellos se pueden identificar a: miembros de la Comunidad Indígena Yagán de Bahía Mejillones que agrupa a descendientes del pueblo yámana, llamados también yaganes, habitantes originarios del área comprendida hoy en la Reserva de Biosfera Cabo de Hornos (Alvarez et al. 2004; Martinic 2006); también se distingue el grupo de residentes antiguos de la isla Navarino que son de la tercera, segunda o primera generación de colonos y que tienen más de 7 años de residencia en Puerto Williams o en otros sectores de la reserva de biosfera; se pueden distinguir también a las personas que tienen períodos de residencia de menor duración (menos de 5 años) que incluyen a la dotación de la Armada de Chile en la Base Naval Beagle, a los funcionarios de servicios públicos locales (Corporación Nacional Forestal, Gobernación Provincial de Puerto Williams,
Servicio Nacional de Pesca, I. Municipalidad Cabo de Hornos), a los profesores del Liceo Donald McIntyre Griffiths, único establecimiento educacional de la ciudad para educación pre-escolar hasta enseñanza media completa, y finalmente a los estudiantes del liceo, que están en su gran mayoría asociados de diversas formas a la Armada de Chile.

Siguiendo las distinciones de grupos socioculturales hechas en la propuesta de Reserva de Biosfera Cabo de Hornos (Rozzi et al. 2006a), se definieron los siguientes seis grupos de entrevistadas: i) residentes antiguos (residentes), ii) miembros de la Comunidad Indígena Yagán de Bahía Mejillones (yaganes), iii) profesores del Liceo Donald McIntyre Griffiths (profesores), iv) autoridades y servicios públicos (autoridades), v) personal asociado a la Armada de Chile (marinos) y vi) estudiantes del Liceo Donald McIntyre Griffiths (estudiantes).

Con el objeto de contar con un número idéntico de entrevistados en cada grupo, se aplicaron 14 entrevistas por grupo puesto que ese fue el número máximo de personas que satisfacía el criterio para cada uno de los grupos ya definidos. Entre junio del 2004 y mayo del 2005 se entregó a cada entrevistado un cuestionario estructurado por escrito (Bernard 1995) que incluía tres preguntas: (1) Escribe el nombre de las 5 primeras aves que recuerdes, (2) Escribe el nombre de las aves que conozcas de la isla Navarino (15 espacios) y 3) ¿Cuáles son las 3 aves de la isla Navarino que más te gustan?

El análisis de la primera pregunta escribe el nombre de las 5 primeras aves que recuerdes, tuvo por objeto caracterizar las aves que están primariamente presentes en la memoria, pensamiento o imaginario de los entrevistados, y distinguir si estas aves corresponden a especies que habitan en el área de la reserva de biosfera, o especies que habitan sólo en otras regiones del país o del planeta. La pregunta dos escribe el nombre de 15 aves que conozcas de la isla Navarino evalúa el conocimiento acerca de un atributo ecológico y de la historia de vida fundamental de las especies: su ámbito de distribución geográfica. Si un entrevistado nombra una especie de ave que no está presente en la isla Navarino, su respuesta expresa un grado de desconocimiento respecto al ave. La pregunta tres cuáles son las 3 aves de la isla Navarino que más te gustan es central para la determinación de la especie carismática. El análisis de los resultados de esta pregunta procura 
identificar a la especie preferida. La preferencia involucra no sólo un conocimiento del nombre, sino que expresa una valoración del ave. Tal valoración puede contemplar una comprensión y/o una emoción acerca de diversos atributos del ave, tales como su estética (por ejemplo, color del plumaje), utilidad (por ejemplo, palatabilidad y valor de la carne del ave), popularidad (por ejemplo, asociación con personajes o caricatura de televisión), valor simbólico (por ejemplo, ave del escudo nacional), rareza (por ejemplo, un ave difícil de observar), por parte de los entrevistados (Arango 2007).

Los cuestionarios se aplicaron de distintas formas de acuerdo al grupo entrevistado: para los residentes, yaganes y profesores se realizó una entrevista personal en la casa del entrevistado donde la persona respondió por escrito el cuestionario. Todas las personas entrevistadas son de nacionalidad chilena. Algunas no respondieron por escrito por diversas razones (9 residentes, 13 yaganes y 2 profesores) y lo hicieron verbalmente a una entrevistadora. El grupo de las autoridades fue entrevistado personalmente en sus lugares respectivos de trabajo. Los marinos respondieron los cuestionarios luego de entregar todas las entrevistas y explicar el procedimiento a un superior de la Base Naval Beagle. Los estudiantes respondieron el cuestionario en una sala del Liceo durante una hora de clases.

A los entrevistados se les solicitó indicar voluntariamente en la pregunta 3 las razones que explicaban sus preferencias. Esto permitió registrar cualidades y observaciones generales acerca de las especies preferidas.

La composición de cada uno de los grupos entrevistados (Arango 2007) dependió de la disponibilidad de las personas, y estuvieron caracterizados de la siguiente manera:

- Los residentes contaron con una mediana de edad de 42 años (rango entre 18 y 70 años). El $21,4 \%$ de ellos eran mujeres y el 78,6\% eran hombres que han vivido en la zona del Cabo de Hornos por más de 7 años. Sus ocupaciones son principalmente la pesca artesanal, algunos son comerciantes y otros desempleados.

- Los yaganes entrevistados son de ascendencia yagán y una persona yagán pura, nacidos en Puerto Williams, otros sectores de la isla Navarino y otras islas de la Región de Magallanes o adyacentes a Argentina (isla Grande de Tierra del Fuego). La mediana de edad de este grupo fue 48 años (con un rango entre 28 y 84 años). El 57,1\% eran mujeres y el $42,9 \%$ hombres cuya permanencia en la zona es de 45,1 años. Son en su mayoría pescadores artesanales y artesanos.

- Los profesores, tuvieron una mediana de edad de 45 años (rango de edad entre 34 y 53 años). En este grupo de entrevistados el porcentaje de mujeres y hombres fue igual y se registró que han permanecido en Puerto Williams por 13,6 años en promedio.

- Las autoridades encuestadas son funcionarios de la Gobernación Antártica Chilena y de la I. Municipalidad de Cabo de Hornos, y los restantes trabajan para los Servicios Públicos. Su mediana de edad es de 33 años (rango de edad entre 25 y 65 años). La proporción de hombres y mujeres entrevistados fue la misma y su permanencia en Puerto Williams es de 11,6 años en promedio.

- Los marinos trabajan para la Armada de Chile del Distrito Naval Beagle. Tienen una mediana de edad de 38 años (rango de edad entre 29 y 48 años). En este grupo el porcentaje de mujeres fue de 21,4 y el de hombres $78,6 \%$ y su permanencia en Puerto Williams es de 2,4 años en promedio.

- Los estudiantes cursaban el cuarto año de Enseñanza Media del Liceo Donald McIntyre de Puerto Williams. La mediana de edad del grupo fue 17 años (rango de edad entre 16 y 17 años). El porcentaje de mujeres entrevistadas fue 71,4 y el de hombres $28,6 \%$ y su permanencia promedio en Puerto Williams es de 6,8 años.

Para evaluar las presencia de diferencias significativas en las respuestas de los grupos socioculturales, para cada una de las preguntas se elaboraron matrices de individuos por aves nombradas y se aplicó un test ANOSIM $^{1}$ (Analysis of Similarities), utilizando el programa estadístico PRIMER versión 5.2.2 para Windows. Cuando existieron diferencias significativas se realizó un test a posteriori comparando cada par de grupos entrevistados utilizando el mismo programa estadístico.

1 El análisis estadístico ANOSIM es un método de permutación no paramétrica aplicado a una matriz de rangos de similitud. Este test entrega un coeficiente de similitud global $\mathrm{R}(-1 \leq \mathrm{R}$ $\leq 1)$ y otro para los pares de comparaciones distinguiendo valores de significancia (Clarke y Gorley 2001). 
Implementación de la especie carismática

A partir de los resultados obtenidos en la investigación descrita en el punto anterior, se determinó que la especie preferida y con potencial carismático corresponde al carpintero gigante o carpintero negro (Campephilus magellanicus). Por esta razón se realizó una extensa revisión bibliográfica acerca de los atributos biológicos y culturales de esta especie incluyendo su potencial para el ecoturismo, estado de conservación, ámbito de distribución, registros etnográficos y trabajo en terreno para determinar atributos con valor para su papel como especie carismática.

Una vez determinado el carácter carismático del carpintero gigante, se emprendió una campaña de difusión, educación y recreación con la comunidad local para reforzar la empatía ya existente hacia la especie, aumentar su conocimiento y elevar su valoración por parte de todos los actores. Para este fin se adaptó la metodología desarrollada por Dietz et al. (1994) para la protección de primates en Brasil, diseñando un plan estratégico que enfatizó la inclusión de los grupos menos familiarizados con la avifauna de la Reserva de Biosfera Cabo de Hornos, y consideró los recursos disponibles en el programa de trabajo del Parque Etnobotánico Omora (Rozzi et al. 2003). Este programa de investigación, educación ambiental y conservación biocultural es conducido por el Programa de Magíster en Ciencias y la Sede Puerto Williams de la Universidad de Magallanes en conjunto con el Instituto de Ecología y Biodiversidad de la Universidad de Chile (IEB), y la Fundación Omora (Rozzi et al. 2006). El modelo de Dietz et al. (1994) provee un proceso sistemático en siete etapas que consideran: 1) identificación de los problemas prioritarios (estatus de conservación de la especie y potenciales amenazas sobre su hábtat), 2) identificación y evaluación de la población objetivo, de los recursos disponibles y del escenario, 3) desarrollo de una interacción positiva con los participantes, 4) selección y análisis de métodos, 5) implementación de actividades, 6) evaluación y 7) reciclaje. Estas siete etapas se adaptaron al caso del carpintero gigante en la Reserva de Biosfera Cabo de Hornos.

El programa de implementación del pájaro carpintero como especie carismática consideró varias instituciones para su puesta en práctica. Las activi- dades de terreno se desarrollaron en los circuitos de senderos guiados del Parque Etnobotánico Omora y las actividades en sala se trabajaron en el Liceo Donald McIntyre, en el contexto del Taller de Historia Natural semanal que el equipo científico del Parque Omora mantiene en forma continua desde el año 2000, y que se ofrece como actividad del plan de estudios enmarcada dentro de la jornada completa del Segundo Ciclo de Enseñanza Básica y al Grupo Scouts. Este Taller desarrolla temáticas ecológicas que se presentan anualmente en la Feria Científica Escolar del Programa EXPLORA-CONICYT, y que en el año 2006 presentó la conservación del carpintero Gigante y los bosques de la isla Navarino. Las Instituciones de Gobierno que participaron con el equipo científico del Parque Etnobotánico Omora fueron: la I. Municipalidad del Cabo de Hornos, el Fondo de Protección Ambiental (FPA) de CONAMA Regional, el Programa EXPLORA-CONICYT, y la Corporación Nacional Forestal (CONAF) Regional. La Gobernación de la Provincia Antártica Chilena y la Armada de Chile apoyaron la ejecución de todas las actividades.

Acciones realizadas para implementar la especie carismática

Las acciones emprendidas para la implementación de la especie carismática consideraron tres ámbitos:

1) Estrategias de educación: Se realizaron talleres de flora y fauna, talleres de ecoturismo y múltiples salidas guiadas a terreno. Para los niños, además del Taller de Historia Natural semanal en el liceo, se diseñaron y montaron obras de teatro, piezas de títeres, $y$ talleres de pintura en terreno en los que participaron también niños de la enseñanza pre-escolar del Jardín Infantil Étnico Ukika (JUNJI). Todos los trabajos de educación consideraron el desarrollo de la ecología, etología y conocimiento tradicional acerca del carpintero Gigante, especialmente los relatos documentados por registros etnográficos antiguos (Gusinde 1986) o recientes (Rozzi et al. 2003a; Zárraga 2005).

2) Desarrollo de material educativo: se diseñaron y publicaron afiches, folletos, videos, CDs, regalos, exposiciones, dibujos, bordados, postales 
y bolsas de tela para compras con imágenes del carpintero gigante.

3) Difusión del trabajo realizado: se mantuvo contacto directo permanente con la comunidad y líderes comunales, autoridades locales (Gobernación de la Provincia Antártica Chilena, I. Municipalidad de Cabo de Hornos, Armada de Chile), directores y funcionarios de agencias de gobierno locales (CO$\mathrm{NAF}$ ) y regionales (CONAF, CONAMA), medios de comunicación (radios, prensa, televisión) y empresas privadas (EDELMAG).

\section{RESULTADOS Y DISCUSIÓN}

Identificación del carpintero gigante como especie carismática para la Reserva de Biosfera Cabo de Hornos

Mediante el análisis ANOSIM se encontró que los grupos socioculturales sobresalientes de Puerto Williams para la pregunta 1: escribe las 5 primeras aves que recuerdes, son significativamente diferentes entre sí $(\mathrm{R}=0,103 ; \mathrm{P}<0,01)$. Para los grupos se encontraron diferencias significativas entre los residentes y marinos $(\mathrm{P}<0,01)$, residentes y autoridades $(\mathrm{P}<0,015)$, y residentes y estudiantes $(\mathrm{P}<$ $0,01)$. Asimismo, hubo diferencias significativas entre yaganes y marinos $(\mathrm{P}<0,01)$, yaganes y estudiantes $(\mathrm{P}<0,02)$, marinos y estudiantes $(\mathrm{P}<0,014) \mathrm{y}$ entre autoridades y marinos $(\mathrm{P}<0,033)$.

De las cinco aves presentes en el imaginario de los grupos socioculturales de Puerto Williams,

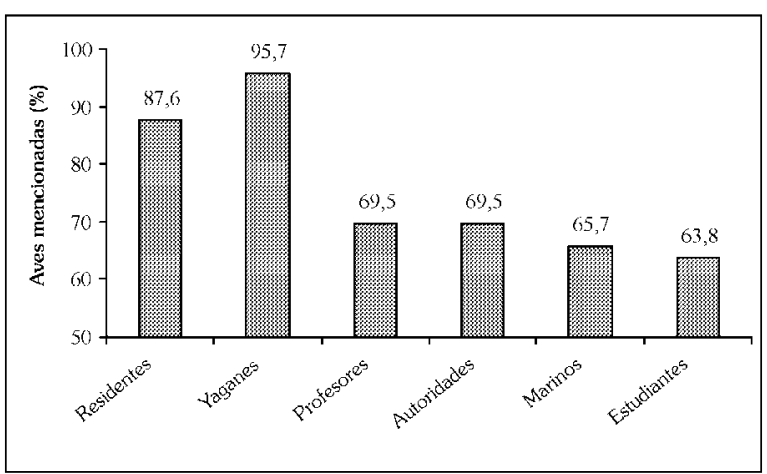

Fig. 1. Porcentaje de aves nativas presentes en la Reserva de Biosfera Cabo de Hornos nombradas por los entrevistados de cada grupo sociocultural de Puerto Williams cuando la pregunta fue: escribe el nombre de las 5 primeras aves que recuerdes. el porcentaje de nominaciones que corresponde a especies nativas y presentes en la isla Navarino se muestra en la Fig. 1. Todas (100\%) las aves nombradas por el grupo yaganes están presentes en el área de la Reserva de Biosfera Cabo de Hornos. Los residentes también nombraron casi exclusivamente especies presentes en el área (98,6\%). El grupo autoridades nombró especies presentes en el área en un $91,4 \%$ y los marinos nombraron especies en un 87,1 . Tanto el grupo de profesores como el de los estudiantes nombraron aves presentes en un $82,9 \%$, es decir, el porcentaje más alto (alrededor del $17,1 \%$ ) de especies ausentes de la isla que eran nativas del sur de Chile, exóticas ausentes de la isla Navarino o introducidas presentes en la isla. En resumen, el imaginario de los profesores, estudiantes y marinos muestra una mayor atención hacia aves de otras regiones, mientras que el imaginario de los yaganes y los residentes antiguos centra su atención en la avifauna regional. El imaginario de las autoridades ocupa un lugar intermedio entre ambos grupos.

Respecto al grado de conocimiento de la avifauna, el análisis de la pregunta 2: escribe el nombre de 15 aves que conozcas de la isla $\mathrm{Na}$ varino, mostró diferencias significativas entre los grupos socioculturales $(\mathrm{R}=0,172 ; \mathrm{P}<0.01)$. El grupo yaganes tuvo el mayor grado de conocimiento de la avifauna, entregando en casi todos los casos 15 nombres de aves que efectivamente se encuentran en el área de la Reserva de Biosfera Cabo de Hornos (Fig. 2). El promedio del número de aves nombradas fue de 14,3 , lo que corresponde al 95,7\% de

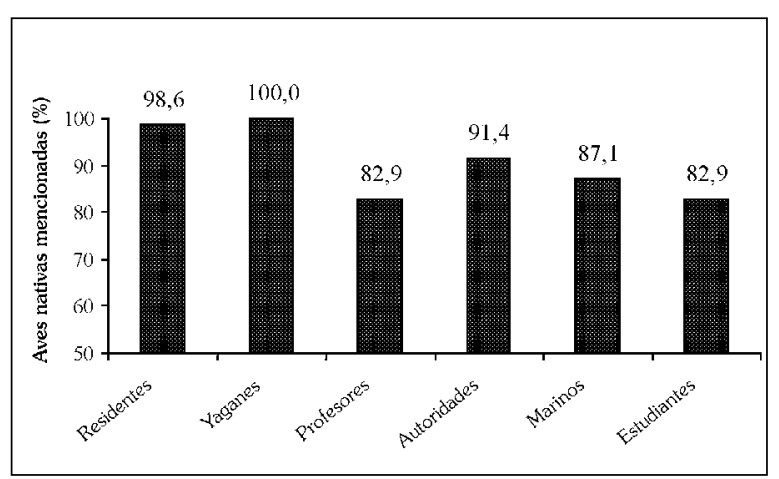

Fig. 2. Porcentaje de aves nombradas (nativas e introducidas) presentes en la isla Navarino nombradas por los entrevistados de cada grupo sociocultural de Puerto Williams cuando la pregunta fue: escribe las 15 aves de la isla Navarino que conozcas. 
las 15 especies de aves solicitadas por la pregunta (Fig. 2). El grupo residentes nombró en promedio 13,2 especies de aves presentes en la reserva en sus respuestas (87,6\%). Este número es menor que el respondido por personas de ascendencia yámana, pero ambos grupos no difieren significativamente $(P>0.05)$. Las autoridades, profesores, marinos y estudiantes nombraron un número de aves significativamente menor que los grupos anteriores, nominando aproximadamente 10 especies en promedio, es decir, contestaron satisfactoriamente entre un 69.5 y $63.8 \%$ de las aves requeridas por la pregunta (Fig. 2). Cabe precisar que para el recuento del número de aves nombradas por cada entrevistado sólo se consideraron aquellas que habitan en la Reserva de Biosfera Cabo de Hornos, incluyendo entre ellas también aves domésticas (gallinas) o urbanas (gorrión y paloma) que aunque no son nativas de la región, sí habitan hoy en Puerto Williams. En conclusión, el grado de conocimiento de la avifauna regional por parte de estos grupos es significativamente menor que el conocimiento albergado por las personas de ascendencia yámana y residentes antiguos de la isla Navarino.

Respecto a la pregunta 3: cuáles son las 3 aves de la isla Navarino que más te gustan, los seis grupos socioculturales mostraron diferencias significativas entre ellos $(R=0,038 ; P<0.04)$. Sin embargo, el test a posteriori muestra que sólo se encuentran diferencias significativas entre profesores y residentes antiguos, entre profesores y marinos, $y$ entre marinos y autoridades. La mayor homogeneidad en la respuesta 3 se debe a que todos los grupos socioculturales incluyeron una misma especie de ave que estuvo entre las especies preferidas: el pájaro carpintero gigante (Campephilus magellanicus).

El carpintero gigante no sólo fue la única ave que se encuentra entre las tres especies preferidas en todos los grupos socioculturales, sino también la especie con mayor porcentaje de preferencia en dos de los seis grupos socioculturales (Fig. 3). Entre los dos grupos con mayor conocimiento ornitológico, los yaganes y los residentes, el carpintero gigante ocupó el primer lugar, seguido por el martín pescador (Ceryle torquata), y por el caiquén (Chloephaga picta) en el grupo yaganes y por el cóndor (Vultur gryphus) en el grupo residentes.

Entre las 38 aves nombradas como especie preferida por algunos de los entrevistados, sólo cuatro especies concentraron más de un $10 \%$ de las preferencias en cada grupo y en el total del universo entrevistado. Considerando el total de las 84 entrevistas, el pájaro carpintero gigante ( $C$. magellanicus) dio cuenta de un $16,7 \%$ de las preferencias, seguido por el caiquén con un $14,2 \%$, el

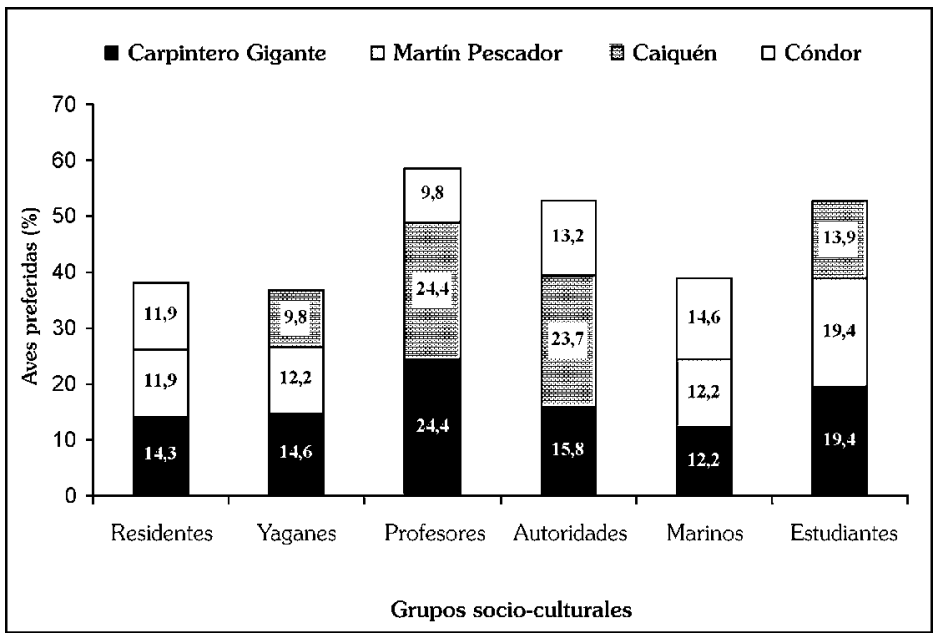

Fig. 3. Porcentaje de preferencia para las 3 especies de aves preferidas por grupo sociocultural de la comunidad de Puerto Williams cuando la pregunta fue: ¿cuáles son las 3 aves de la isla Navarino que más te gustan?. Aunque las respuestas incluyeron 38 especies, sólo 4 de ellas estuvieron incluidas entre las 3 especies de aves preferidas por los seis grupos socioculturales: el carpintero Gigante (Campephilus magellanicus), el martín Pescador (Ceryle torquata), el cóndor Andino (Vultur gryphus) y el caiquén (Cloephaga picta). 
martín pescador con un 12,1\%, y el cóndor andino con $10,8 \%$. Esta última especie fue la preferida por los marinos, aspecto que según las entrevistas no estructuradas estaría vinculado a la presencia del cóndor en el escudo nacional. El cóndor también fue una de las especies preferidas por las autoridades y los profesores por la misma razón. El martín pescador estuvo entre las tres especies preferidas en cuatro de los seis grupos socioculturales, quienes expresaron su atractivo y colorido plumaje. El caiquén fue nombrado también por cuatro grupos, y la preferencia estaría vinculada a la abundancia de esta ave, su belleza, fácil avistamiento y su uso comestible (algunos entrevistados indicaron el gusto por comer el ave y/o sus huevos).
En resumen, el pájaro carpintero gigante fue la única especie de ave preferida por todos los grupos, alcanzó también el mayor grado de preferencias en el total y fue la predilecta para las personas que llevan más tiempo viviendo en el Cabo de Hornos y que poseen el mayor conocimiento de la avifauna que habita en la Reserva de Biosfera Cabo de Hornos. Por lo tanto, esta especie fue considerada como la primera opción para ser la especie carismática de esta región.

Se definieron entonces los atributos para nominar a esta especie como carismática (Tabla 1). Entre las razones que las personas señalaron para preferir al carpintero gigante se registró su valor estético, su rareza (sólo se la ve ocasionalmente), y los llamativos movimientos de picoteo. Se destacó

Tabla 1. Criterios para nominar al carpintero gigante (Campephilus magellanicus) como especie carismática en la Reserva de Biosfera Cabo de Hornos.

\begin{tabular}{|c|c|c|}
\hline Criterio & Fundamentación & Referencias \\
\hline $\begin{array}{l}\text { (1) Carácter } \\
\text { carismático }\end{array}$ & $\begin{array}{l}\text { Tradicionalmente las aves y mamíferos han sido especies carismáticas ideales; } \\
\text { la comunidad local de Puerto Williams prefiere al carpintero gigante por sobre } \\
\text { el resto de las aves de la isla Navarino. }\end{array}$ & $\begin{array}{l}\text { Arango (2007); } \\
\text { Arango y Rozzi } \\
(2005)\end{array}$ \\
\hline $\begin{array}{l}\text { (2) Asociado en } \\
\text { forma positiva por } \\
\text { la comunidad local }\end{array}$ & $\begin{array}{l}\text { El carpintero gigante posee solamente atributos positivos para la comunidad } \\
\text { de Puerto Williams. }\end{array}$ & $\begin{array}{l}\text { Arango y Rozzi } \\
(2004,2005)\end{array}$ \\
\hline $\begin{array}{l}\text { (3) Especie relevante } \\
\text { para el pueblo yagán }\end{array}$ & $\begin{array}{l}\text { Para la etnia yagán, el carpintero gigante llamado lana, reviste especial impor- } \\
\text { tancia en cuanto constituye un ave conspicua en los bosques donde las mujeres } \\
\text { yaganes solían recolectar dihüeñes. }\end{array}$ & $\begin{array}{l}\text { Rozzi et al. (2003a) } \\
\text { Rozzi (2004) }\end{array}$ \\
\hline $\begin{array}{l}\text { (4) Atributos } \\
\text { ecológicos esenciales } \\
\text { para la conservación }\end{array}$ & $\begin{array}{l}\text { El carpintero gigante es: i) especie clave, puesto que construye cavidades que } \\
\text { sirven de sitios de nidificación y pernoctación para un conjunto de especies de } \\
\text { aves, tales como búhos y loros; ii) especie indicadora de bosques antiguos, puesto } \\
\text { que sólo habita en ecosistemas forestales con abundantes bosques maduros; iii) } \\
\text { especie paraguas para la conservación de la biodiversidad, puesto que posee } \\
\text { un ámbito de hogar relativamente extenso. Por lo tanto, al proteger su hábitat } \\
\text { se conservan comunidades bióticas completas. }\end{array}$ & $\begin{array}{l}\text { McBride (2000); } \\
\text { Ojeda (2004); Rozzi } \\
\text { et al. }(2003 a) \\
\text { Arango y Rozzi } \\
(2005)\end{array}$ \\
\hline $\begin{array}{l}\text { (5) Reconocimiento } \\
\text { por parte de la } \\
\text { comunidad local }\end{array}$ & $\begin{array}{l}\text { Al carpintero gigante se le atribuye un carácter popular al ser el ave más conocida } \\
\text { por la comunidad de Puerto Williams, siendo la primera entre las } 15 \text { especies de } \\
\text { aves que las personas conocen de la isla Navarino. }\end{array}$ & Arango (2007) \\
\hline $\begin{array}{l}\text { (6) Identidad del } \\
\text { Cabo de Hornos } \\
\text { como cumbre } \\
\text { austral de América }\end{array}$ & $\begin{array}{l}\text { La población de Campephilus magellanicus que habita en los bosques de la Re- } \\
\text { serva de Biosfera Cabo de Hornos corresponde a los sobrevivientes más australes } \\
\text { de este género de pícidos que sólo habita en el Continente Americano. }\end{array}$ & Rozzi et al. (2004) \\
\hline $\begin{array}{l}\text { (7) Valor intrínseco } \\
\text { en historias de } \\
\text { la etnia yagán }\end{array}$ & $\begin{array}{l}\text { El origen de esta especie proviene, de acuerdo a las historias de la cosmología } \\
\text { yagán, de tiempos ancestrales cuando las aves todavía eran humanas. }\end{array}$ & $\begin{array}{l}\text { Rozzi et al. (2003a) } \\
\text { Rozzi (2004) }\end{array}$ \\
\hline $\begin{array}{l}\text { (8) Congénere del } \\
\text { extinto carpintero } \\
\text { más grande } \\
\text { del mundo. }\end{array}$ & $\begin{array}{l}\text { Campephilus magellanicus es congénere del carpintero imperial ( } C \text {. imperialis), } \\
\text { el más grande del mundo extinto hoy por la pérdida de su hábitat y del potencial- } \\
\text { mente extinto carpintero real (C. principalis). Esto hace que su conservación sea } \\
\text { una prioridad dado que es el sobreviviente más austral de su género. }\end{array}$ & Winkler et al. (1995) \\
\hline $\begin{array}{l}\text { (9) Distribución } \\
\text { geográfica }\end{array}$ & $\begin{array}{l}\text { Campephilus magellanicus habita en los bosques antiguos de la Reserva de Bios- } \\
\text { fera Cabo de Hornos, especialmente en sectores protegidos del viento donde se } \\
\text { conservan bosques no fragmentados de Nothofagus pumilio y N. betuloides. }\end{array}$ & Rozzi et al. (2004) \\
\hline $\begin{array}{l}\text { (10) Estatus de } \\
\text { conservación }\end{array}$ & $\begin{array}{l}\text { La especie ha sido catalogada como vulnerable a nivel nacional y en peligro de } \\
\text { extinción en las VI,VII y VIII regiones de Chile. }\end{array}$ & Glade (1993) \\
\hline
\end{tabular}


también su popularidad al asociarlo con la caricatura estadounidense creada por Joseph Hardaway el pájaro loco (Woody Woodpecker) (Arango y Rozzi 2005). Igualmente, otras personas le adjudicaron valores humanos (laboriosidad) y se le identificó como típico de la región. Más tarde se determinaron los aspectos ecológicos, socioeconómicos y culturales que el carpintero Gigante podría poseer para constituirse en una especie carismática idónea (Tabla 1).

Cabe destacar que este estudio identifica por primera vez en Chile una especie carismática a partir de las preferencias de la comunidad local, determinándose en forma cuantitativa que Campephilus magellanicus es la primera especie candidata a ser especie carismática de la Reserva de Biosfera Cabo de Hornos. Esta ave fue la más nombrada y valorada positivamente por la comunidad local (Arango y Rozzi 2005). En nuestro caso, la identificación de una especie carismática para la Reserva de Biosfera Cabo de Hornos se ha desarrollado desde la percepción local, y no a partir de criterios estéticos o ecológicos definidos a priori.

Atributos del pájaro carpintero Gigante como especie carismática en la Reserva de Biosfera Cabo de Hornos

Desde el punto de vista de su significación cultural, el pájaro carpintero Gigante no sólo posee una importancia para la comunidad actual de Puerto Williams, sino también los registros etnográficos indican su presencia en las historias yaganes de aves del bosque. El carpintero o lana en lengua yagán, habita en los bosques del archipiélago del Cabo de Hornos donde acompañaba a las mujeres que solían recolectar hongos dihueñes (Cyttaria sp.) (Rozzi et al. 2003a). De acuerdo al relato del abuelo yagán Juan Calderón: el origen de esta hermosa ave se remonta a tiempos ancestrales, cuando todavía los pájaros eran humanos.

En aquellos tiempos, un chico se enamoró de su hermana y procuraba cualquier triquiñuela para encontrarse y dormir junto a ella. Su hermana había notado esta intención y esquivaba a su hermano cada vez que él la buscaba, evitando relaciones prohibidas, pero en el fondo ella también quería estar junto a él, y a la vez no. El hermano, seguía pensando en pretextos para atraerla fuera del akar o ruca. Un día descubrió grandes frutos de chaura roja, en el claro de un bosque y fue raudamente a contarle a su hermana: he encontrado enormes chauras en un lugar del bosque, deberías ir y recogerlas. La hermana tomó presta su canasto y se internó en el bosque, mientras su hermano la siguió sin que nadie lo notara y se escondió en un lugar cerca donde tendría que pasar su hermana. Una vez que ella había llegado, él se lanzó y la abrazó, y juntos cayeron al suelo dando curso a su amor. Cuando se levantaron se convirtieron en pájaros y volaron como lana. Desde entonces viven juntos en los bosques y el hermano lleva sobre su cabeza un penacho rojo que recuerda el color de aquellos grandes frutos de la chaura.

Este relato expresa la cercanía entre la vida de esta ave y de las personas de la etnia yámana. El inicio de este relato cuando las aves todavía eran humanos, y la transformación de la pareja de hermanos en pájaros carpinteros, expresan también una noción de parentesco genealógico entre las aves y los seres humanos. Aunque expresada de manera diferente por la teoría evolutiva científica, la genealogía común entre aves y seres humanos implica un sentido de parentesco, que podría estimular una mayor consideración ética por el valor intrínseco de esta ave (Rozzi 2004).

Desde el punto de vista de su valoración popular, como ya se mencionó, el carpintero Gigante se asocia con la caricatura del pájaro loco, que fue una representación del carpintero norteamericano Dryocopus pileatus.

Desde el punto de vista del valor para la conservación de la biodiversidad, Campephilus magellanicus podría ser la especie más cercana evolutivamente a la especie que fuera el pájaro carpintero más grande del mundo: el carpintero imperial (Campephilus imperialis), extinto en el Hemisferio Norte por alteración de su hábitat y presión de caza. Por lo tanto, C. magellanicus representa un linaje de alto valor y una inspiración para la conservación. A nivel nacional en Chile, esta especie presenta problemas de conservación y se encuentra en categoría vulnerable (Glade 1993).

Para el ecoturismo, el parentesco del carpintero gigante con el carpintero imperial y el hecho de ser el pájaro carpintero más grande de Sudamérica posee un gran atractivo para los birdwatchers. Entre los visitantes de turismo de naturaleza a la Región de Magallanes, el pájaro carpintero gigante sea una 
de las especies más solicitadas por los visitantes extranjeros (Ricardo Matus, comunicación personal). Tanto desde el punto de vista de la conservación como del turismo, es interesante que el carpintero gigante es una especie endémica de los bosques templados del sur de Chile y Argentina (Couve y Vidal 2003). Por estas razones, su implementación como especie carismática podría potenciar los ingresos económicos por turismo en la Reserva de Biosfera Cabo de Hornos.

Finalmente, desde el punto de vista ecológico, tres atributos esenciales hacen al carpintero Gigante una especie carismática ideal: a) es una especie clave puesto que construye sitios de nidificación para otras especies de aves, y controla también las poblaciones de larvas de insectos en los troncos de árboles del género Nothofagus; b) es una especie indicadora de bosques antiguos, puesto que para construir sus cavidades y para alimentarse de larvas requiere árboles antiguos, y los bosques antiguos poseen un especial valor para conservación de la biodiversidad; c) constituye una especie paraguas puesto que se trata de una especie residente que establece territorios con ámbitos de hogar más extensos que el de otras especies de aves que residen en los bosques subantárticos; por lo tanto, la protección de hábitat del pájaro carpintero Gigante protege también el hábitat de muchas otras especies con requerimientos de área menor.

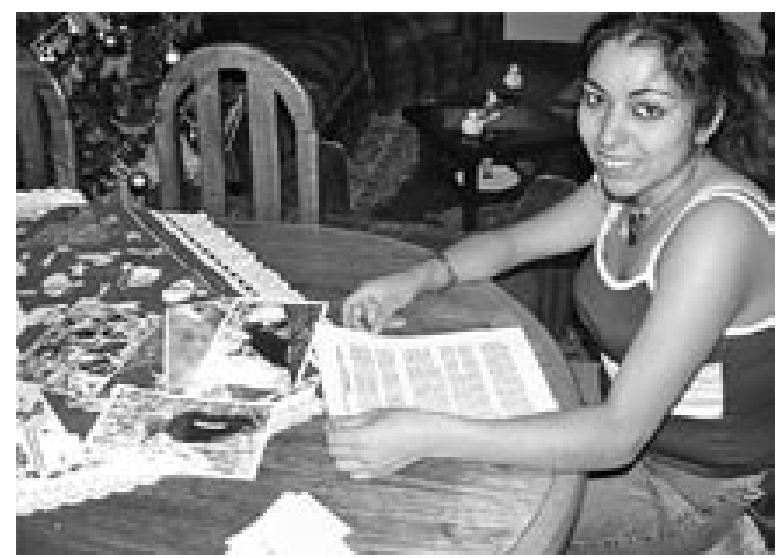

La Tabla 1 presenta una síntesis de los 10 atributos que constituyen a C. magellanicus en una especie carismática ideal para la Reserva de Biosfera Cabo de Hornos. Una vez, identificado este conjunto de atributos se decidió comunicar a la comunidad de Puerto Williams y de la Región de Magallanes el valor de implementar de esta especie para la conservación de la diversidad biológica y cultural, y de la identidad regional.

Implementación del pájaro carpintero gigante como especie carismática en la Reserva de Biosfera Cabo de Hornos

Los esfuerzos del Programa de Implementación del Carpintero Gigante se dedicaron a aumentar el conocimiento de la especie y de su hábitat, junto con el conocimiento de sus interacciones ecológicas, en acciones dirigidas hacia los diversos sectores de la población de Puerto Williams. La población se sintió atraída por los temas ecológicos y se despertó interés y entusiasmo por el hecho que además de constituir un orgullo local al ser un pájaro bello y raro, el carpintero Gigante podría estar asociado a ventajas económicas a través del fomento del turismo en la localidad (Fig. 4a,b).

Sin duda una de las interacciones más importantes ha sido la asociación con el Liceo Donald McIntyre y el jardín infantil de la JUNJI. A través

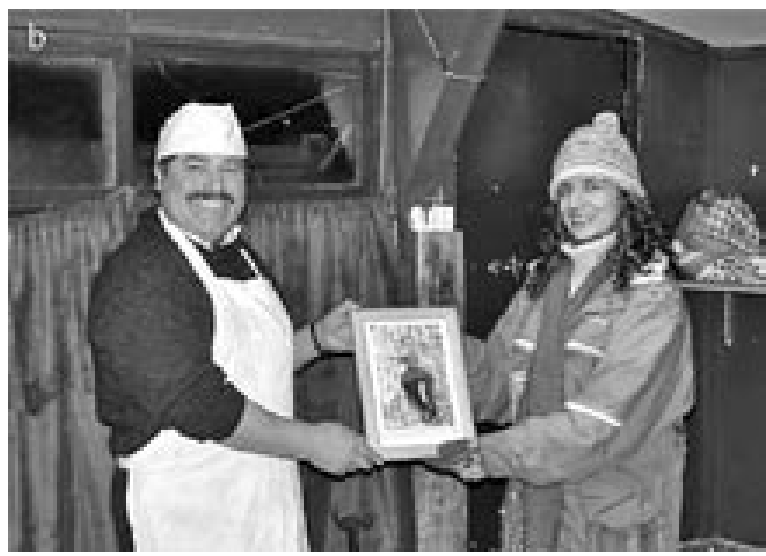

Fig. 4. a) En enero del 2005 se entregaron a la artesana local, Alejandra Guanel, fotografías del carpintero Gigante con información sobre su historia natural y ecología. Alejandra ocupó estas fotografías para la elaboración de bordados con motivos novedosos para vender a la gente local y a los turistas. b) Algunas personas de la comunidad local solicitaron fotografías del pájaro carpintero para exhibirlas en sus locales comerciales. El residente y propietario de restaurante en Puerto Williams, Víctor Hugo Henríquez, recibe las fotografías para exponerlas en El albatros, su local comercial. Estos representan sólo un ejemplo de las muchas actividades desarrolladas en la comunidad local (Fotos Ximena Arango y Christopher Anderson). 
de este trabajo ha sido posible sensibilizar a una parte importante del sector adulto de la población a través de sus hijos. Además, como hay un solo liceo en Puerto Williams, los niños pertenecen a familias incluidas en todos los grupos socioculturales. Por lo tanto, el trabajo con los niños y niñas tuvo un papel esencial para la difusión del Programa de Implementación de esta especie de ave (Fig. 5).

Para la difusión regional fue muy importante contar con los medios de comunicación para reforzar al carpintero gigante como un símbolo de la Reserva de Biosfera Cabo de Hornos. Además, se diseñaron y publicaron afiches, folletos, videos, CDs, regalos, exposiciones, dibujos, bordados, postales y bolsas de tela para compras con imágenes del carpintero Gigante. La bolsa de tela ha sido un artículo especialmente relevante porque se enmarca en el programa saquémosle la mugre a Puerto Williams organizado por la I. Municipalidad de Cabo de Hornos que procura reducir el uso de bolsas plásticas desechables, junto con crear conciencia de la necesidad de proteger y mantener limpios los bosques más australes del planeta (Fig. 6). El Programa de Implementación del Carpintero Gigante interesó y entusiasmó a las autoridades de la Armada de Chile animándolos a ocupar la imagen del carpintero como símbolo en su propia campaña ambiental que aportaría a la reducción de las bolsas plásticas en la reserva de
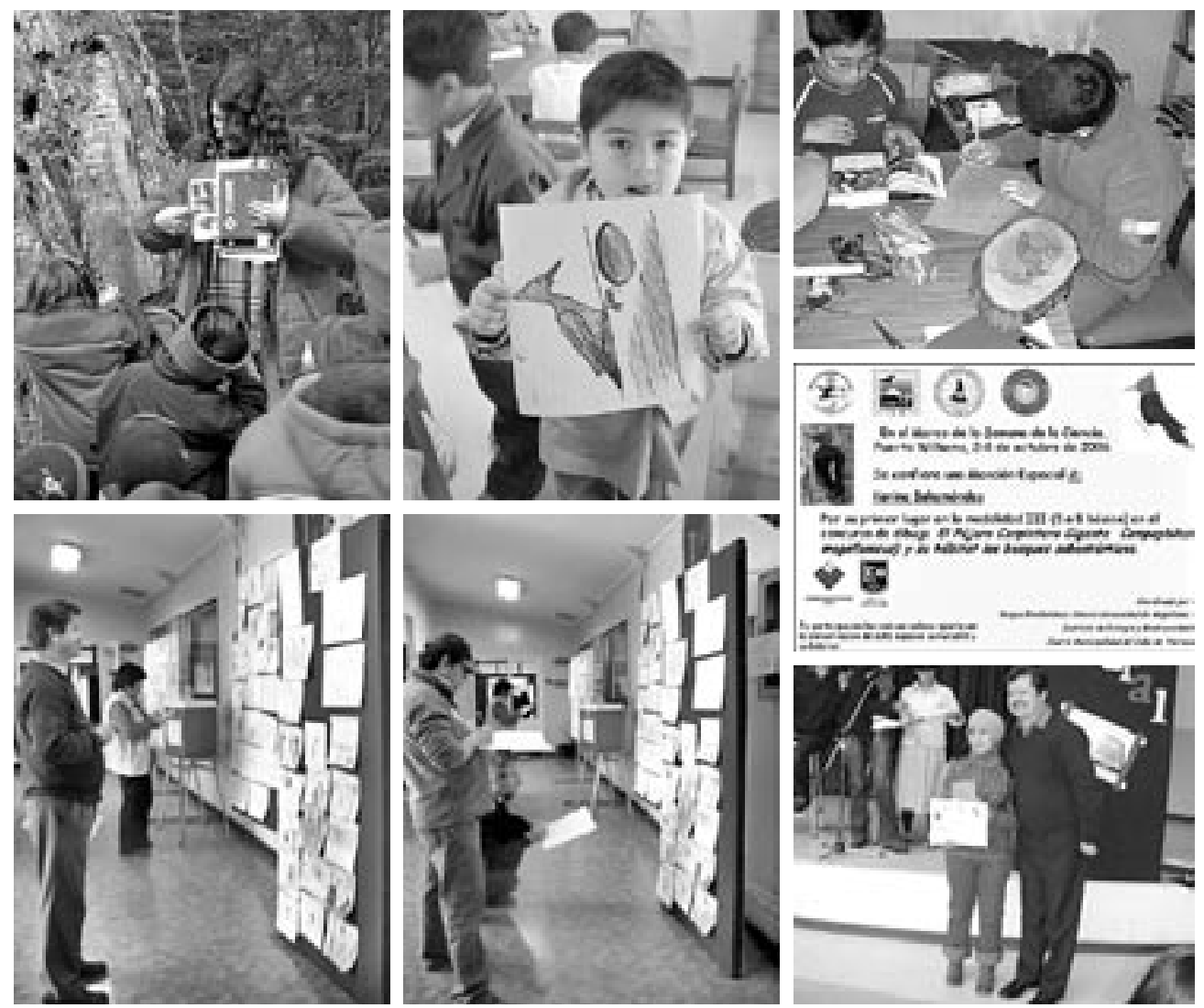

Fig. 5. Etapas del Concurso de Dibujo El Carpintero y su hábitat organizado por el Programa de Implementación del

Carpintero Gigante para la comunidad de Puerto Williams. Los niños visitaron repetidamente el Parque Omora donde conocieron el hábitat del carpintero Gigante y ocasionalmente avistaron algunos individuos. Luego dibujaron en sala en el liceo lo que habían visto en terreno y más tarde expusieron sus trabajos al público. Los líderes comunales José Soto Passek, Alcalde de la Comuna Cabo de Hornos, Julia González, miembro de la Comunidad Indígena Yagán, Francisco Gascogne, Jefe de Área Cabo de Hornos de la Corporación Nacional Forestal (CONAF) y Claudio Yánez, Segundo Comandante del

Distrito Naval Beagle, participaron activamente como jurados calificadores del concurso. Los niños y niñas ganadores

del concurso recibieron premios y diplomas de manos del Alcalde. La activa participación de los distintos sectores de la comunidad local es fundamental para el éxito de este Programa de Implementación (Fotos Ximena Arango y Rina Charlín). 

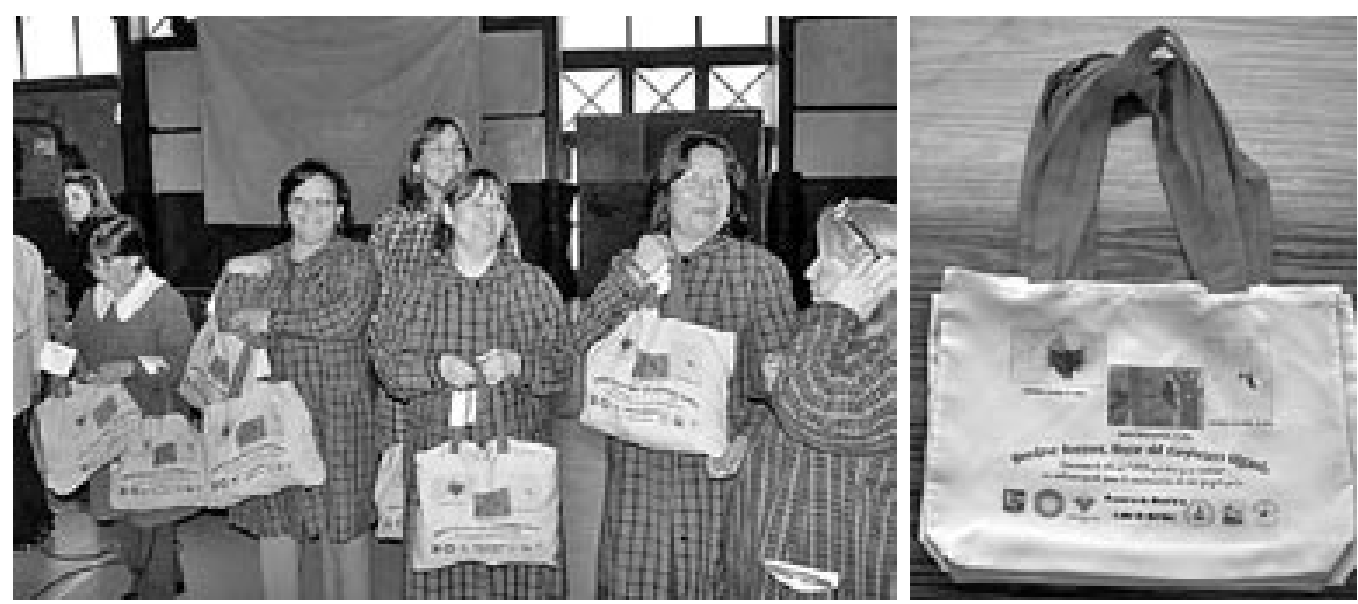

Fig. 6. En abril del 2007, el Programa de Implementación del Carpintero Gigante en coordinación con la I. Municipalidad de Cabo de Hornos, inauguraron el Mes de la Tierra en el Liceo Donald McIntyre de Puerto Williams. A la ceremonia asistieron todos los estudiantes, sus profesores, las directivas del liceo y el Alcalde de la Comuna. En esa oportunidad el Programa de Implementación hizo entrega de 300 bolsas de tela con los dibujos del carpintero Gigante que habían ganado el concurso El Carpintero y su hábitat. El objeto de este regalo a la comunidad fue iniciar la campaña de disminución del uso de bolsas de plástico. Cada una de las familias con hijos en el Liceo recibió una bolsa. En la fotografía un grupo de profesoras posa con las bolsas que fueron financiadas por el Programa de Difusión de la Ciencia del Instituto de Ecología y Biodiversidad y el Parque Etnobotánico Omora. (Fotos Mauricio Bahamonde y Ximena Arango).

biosfera. Es relevante notar que el grupo marinos tuvo el porcentaje más bajo de preferencia hacia el carpintero, según las entrevistas (Fig. 3). Las principales etapas del proceso de implementación del carpintero se sintetizan en el Apéndice I.

\section{CONSIDERACIONES FINALES Y CONCLUSIONES}

Este trabajo demuestra que existen diferencias significativas respecto al grado de conocimiento de la diversidad de aves, y probablemente de la biota en general entre los distintos grupos socioculturales que componen la población de Puerto Williams. Sin embargo, coincidieron en la elección del pájaro carpintero gigante como una especie predilecta entre las aves, por lo tanto, el carpintero Gigante tiene una capacidad de apelar a distintos sectores y reunirlos en una acción común por un desarrollo turístico que sea sustentable, que genere ingresos para la comunidad y que promueva la conservación de la biodiversidad.

Las especies que atraen la atención de la gente, como el carpintero gigante, tienen un alto potencial para motivar acciones de conservación tanto de la especie como de su hábitat. La conservación de estas especies llamativas ayuda a proteger también toda la diversidad de vida que descansa bajo su sombra. Así, al proteger al carpintero se conservan también todas las especies de plantas y animales que habitan en los bosques antiguos, con sus ríos y reservas de suelos fértiles para la isla Navarino y la Reserva de Biosfera Cabo de Hornos. El programa de trabajo en especies carismáticas del Parque Etnobotánico Omora tuvo como primer objetivo definir cuáles eran estas especies para la comunidad local. Sólo una vez que se descubrió al carpintero gigante como especie carismática, se inició la implementación para lograr el apoyo público para $C$. magellanicus a través de acciones de educación y difusión dirigidas a la comunidad local, y que permitieron la toma de conciencia y la valoración de esta especie y de los bosques donde habita por parte de la comunidad local. Las acciones que se emprendieron involucraron mayoritariamente a los escolares y residentes permanentes de la reserva de biosfera, ya que su apropiación con la especie es clave para que el esfuerzo del programa de implementación perdure en el tiempo.

En suma, este trabajo permite concluir que:

1. Los grupos socioculturales de Puerto Williams presentan diferencias significativas en sus preferencias hacia las aves de la zona pero concuerdan en sus preferencias hacia el carpintero gigante. 
2. El carpintero gigante fue especialmente preferido para los miembros de la Comunidad Indígena Yagán y para los residentes antiguos, quienes son las personas que llevan más tiempo viviendo en la región del Cabo de Hornos y las que tienen un mayor conocimiento de la avifauna local.

3. El carpintero gigante (C. magellanicus) es una especie carismática para la población de Puerto Williams.

4. Esta investigación definió diez criterios que hacen del carpintero gigante una especie carismática ideal para motivar acciones de conservación concretas en favor de la conservación de los bosques antiguos de la Reserva de Biosfera Cabo de Hornos.

5. Las actividades realizadas en el Programa de Implementación del carpintero gigante, en combinación con los materiales de difusión concretos diseminaron el conocimiento ecológico y la valoración del carpintero gigante a distintas escalas (local, regional, nacional e internacional), principalmente a nivel local.

6. Las actividades de educación ambiental realizadas y los materiales de difusión generados en el Programa de Implementación del Carpintero Gigante demuestran que es posible una aplicación del conocimiento generado por la investigación ecológica, y enfatizan que la transdisciplina de la conservación biológica y cultural requiere de un proceso participativo donde el conocimiento se genera y se utiliza en conjunto. Este proceso de investigación y aplicación ha permitido construir el apoyo público hacia el carpintero gigante, que redunda en beneficio de la protección de los bosques subantárticos de Magallanes y de las oportunidades para una economía sustentable para la comunidad en la Reserva de Biosfera Cabo de Hornos.

\section{AGRADECIMIENTOS}

Agradecemos la contribución de todas las personas que participaron en el Programa de Implementación del Carpintero. El trabajo tuvo el apoyo del proyecto BIOKONCHIL (Subproyectos 1 y 3, BMBF, №-FKZ01LM0208, German Ministry of Education and Research), y del Instituto de Ecología y Biodiversidad IEB (№-P02-051-FICM).
Agradecemos la colaboración del Parque Etnobotánico Omora, Fundación Omora, Programa de Difusión de la Ciencia del Instituto de Ecología y Biodiversidad, Universidad de Magallanes, Liceo Donald McIntyre de Puerto Williams, Jardín Infantil Étnico Villa Ukika, I. Municipalidad de Cabo de Hornos, Armada de Chile, Gobernación de la Provincia Antártica Chilena, CONAMA, CONAF, SERNATUR y EXPLORA-CONICYT. Ximena Arango Estévez agradece al Instituto de Ecología y Biodiversidad la Beca de Magíster del Proyecto ICM (P05-002).

\section{REFERENCIAS}

ÁLVAREZ R., F. MASSARDO, R. ROZZI, U. BERGHÖEFER, A. BERGHÖEFER y J. FREDES. 2004. Patrimonio Cultural de la Reserva de Biosfera Cabo de Hornos Propuesta. En: Rozzi, R., F. Massardo \& C. Anderson (eds.). 2004. The Cape Horn Biosphere Reserve: A Proposal for Conservation and Tourism to Achieve Sustainable Development at the Southern End of the Americas. Bilingual English-Spanish Edition. Ediciones Universidad de Magallanes, Punta Arenas, Chile, pp. 153-177.

ANDERSON, C, R. ROZZI, J.C. TORRES-MURA, S. MCGEHEE, M. SHERRIFFS, E. SCHUETTLER \& A. ROSEMOND. 2006. Exotic vertebrate fauna of the remote and pristine sub-Antarctic Cape Horn Archipelago, Chile. Biodiversity and Conservation 15: 3295-3313.

ARANGO, X. 2007. El pájaro carpintero Gigante (Campephilus magellanicus, King 1828): una especie carismática al fin del mundo y su implementación para la conservación de los bosques antiguos de la Reserva de Biosfera Cabo de Hornos. Tesis Programa de Magíster en Ciencias, Universidad de Magallanes, Punta Arenas. MS.

ARANGO, X y R. ROZZI. 2004. El carpintero Gigante (Campephilus magellanicus): una especie carismática al fin del mundo. En: Libro de Resúmenes de la II Reunión Binacional Chile-Argentina de Ecología, Mendoza, pp: 239.

ARANGO, X y R. ROZZI. 2005. El carpintero Gigante (Campephilus magellanicus): una especie carismática al fin del mundo. En: vivir en la isla Navarino: un mundo diverso en el fin del mundo. Proyecto BIOKONCHIL (Ministerio de Educación e Investigación, BMBF, N01LM0208), pp: 47-54.

BERNARD, H. R. 1995. Research Methods in Anthropology. Qualitative and Quantitative Approaches. Altamira Press, Inc., Walnut Creek. 
CLARKE, K.R., y R.N. GORLEY. 2001. PRIMER v5: User manual/tutorial. PRIMER-E, Plymouth, UK.

COUVE, E. y C. VIDAL. 2003. Aves de la Patagonia, Tierra del Fuego y Península Antártica. Editorial Fantástico Sur Birding Ltda., Punta Arenas.

DIETZ J. M., L. A. DIETZ y E. Y NAGAGATA. 1994. The effective use of flagship species for conservation of biodiversity: the example of Lion Tamarins in Brazil. En: Creative Conservation: Interactive Management of Wild and Captive Animals, (P.J.S Olney, G. M. Mace y A. T. C. Feistner, eds.) Chapman \& Hall, London, pp: 32-49.

GLADE, A. 1993. Libro Rojo de los Vertebrados Terrestres de Chile. Segunda Edición Corporación Nacional Forestal (CONAF). Ministerio de Agricultura, Santiago.

GUSINDE, M. 1986. Los Indios de Tierra del Fuego. Tomo Segundo: Los Yámana. Centro Argentino de Etnología Americana. 1 y 2, Buenos Aires.

HEYWOOD, V. H (ed). 1995. Global Biodiversity Assesment. Cambridge University Press, Cambridge.

KLEIMAN, D G; BECK, B B; DIETZ, J M; DIETZ, L A; BALLOU, J D; COIMBRA-FILHO, A F. 1987. Conservation program for the golden lion tamarin: captive research and management, ecological studies, education strategies, and reintroduction. En: (eds. Benirschke, K.) Primates: The Road to Self-Sustaining Populations. Springer-Verlag, New York, pp: 959-979.

KRÜGER O. 2005. The role of ecotourism in conservation: panacea or Pandora's box?. Biodiversity and Conservation 14: 579-600.

LEADER-WILLIAMS, N y H. T. DUBLIN. 2001. Charismatic Megafauna as Flagship Species. En: Priorities for the Conservation of Mammalian Diversity. Has the Panda had its Day?, (eds. A. Entwistle y N. Dunstone), Cambridge University Press, London.

MARTINIC, M. 2006. Crónica de las Tierras del Sur del Canal Beagle. Ediciones Hotel Lakutaia, Punta Arenas.

McBRIDE, P. 2000. Magellanic Woodpecker (Campephilus magellanicus) Habitat Selection in Deciduous Nothofagus Forests of Tierra del Fuego. Unpublished master's thesis, Western Washington University. MS.

MEFFE, G. K y C. R CARROLL (eds.). 1997. Principles of Conservation Biology. Sinauer Associates Inc. Publishers, Sunderland, Massachusetts.

MITTERMEIER R. A. 1986. Primate conservation priorities in the Neotropical region. En: Primates - The Road to Self - Sustaining Populations, (ed. E. Benirschke), Springer - Verlag, New York, pp: 221-240.

MITTERMEIER, R., C. MITTERMEIER, J. PILGRIM, G.
FONSECA, W. KONSTANT y T. BROOKS. 2002. Wilderness. Earth's Last Wild Places, (ed. P. Robles), CEMEX-Conservation International, Washington DC.

NAIDOO, R. y W. L. ADAMOWICZ. 2005. Economic benefits of biodiversity exceed costs of conservation at an African rainforest reserve. Proceedings of the National Academy of Sciences 102:16712-16716.

OJEDA, V. 2004. Breeding biology and social behaviour of Magellanic Woodpeckers (Campephilus magellanicus) in Argentine Patagonia. European Journal of Wildlife Research 50: 18-24.

PISANO, E. 1977. Fitogeografía de Fuego Patagonia chilena. I. Comunidades vegetales entre las latitudes $52^{\circ}$ y $56^{\circ} \mathrm{S}$. Anales del Instituto de la Patagonia 8: 121-250.

PRIMACK, R y F. MASSARDO. 2001. Estrategias de Conservación ex situ. En: Primack, R., R. Rozzi, P. Feinsinger, P, R. Dirzo y F. Massardo. Fundamentos de Conservación Biológica. Fondo de Cultura Económica, México, pp: 421-446.

ROZZI, R. 2004. Implicaciones éticas de narrativas yaganes y mapuches sobre las aves de los bosques templados de Sudamérica austral. Ornitología Neotropical 15: 435-444.

ROZZI, R., F. MASSARDO y O. DOLLENZ. 2003. Un Programa de Investigación, Educación y Conservación Biocultural a Largo Plazo en el Extremo Austral de América. Austro Universitaria 14: 50-59.

ROZZI, R., F. MASSARDO, C, ANDERSON, S. McGEHEE, G. CLARK, G. EGLI, E. RAMILO, U. CALDERON, C. CALDERON, L. AILLAPAN, y C. ZARRAGA. 2003a. Guía Multiétnica de Aves de los Bosques Templados de Sudamérica Austral. Fantástico Sur - Universidad de Magallanes, Punta Arenas.

ROZZI, R., F. MASSARDO y C. ANDERSON (eds). 2004. Reserva de Biosfera Cabo de Hornos. Una Propuesta de Conservación y Turismo en el Extremo Austral de América. Ediciones Universidad de Magallanes. Punta Arenas, Chile.

ROZZI, R., F. MASSARDO, C. ANDERSON, K. HEIDINGER y J. SILANDER JR. 2006. Ten Principles for Biocultural Conservation at the Southern Tip of the Americas: The Approach of the Omora Ethnobotanical Park. [online] URL: http://www.ecologyandsociety.org/vol11/iss1/ art43/. Ecology \& Society 11(1): 43.

ROZZI, R., F. MASSARDO, C. ANDERSON, A. BERGHOEFER, A. MANSILLA, M. MANSILLA, J. PLANA, U. BERGHOEFER, E. BARROS y P. ARAYA. 2006a. The Cape Horn Biosphere Reserve. Ediciones Universidad de Magallanes, Punta Arenas. 
SILANDER, J. A., JR. 2000. Temperate forests: plant species biodiversity and conservation. En: Encyclopedia of Biodiversity. (ed S.A. Levin) Academic Press, New York, 5: 607-626.

SIMBERLOFF, D. 1998. Flagships, Umbrellas, and keystones: is single species management passé in the landscape era?. Biological Conservation 83: 247-257.

WALPOLE, M. J y N. LEADER-WILLIAMS, 2002. Tourism and flagship species in conservation. Biodiversity and Conservation 11: 543-547.
WINKLER, H., D. CHRISTIE y D. NURNEY. 1995. Woodpeckers. Ed. Houghton Mifflin Company, Boston.

ZÁRRAGA, C. 2005. Úrsula Calderón y Cristina Calderón: hai kur, mamashu shis (Quiero Contarte un Cuento). Ediciones Kultrún, Valdivia. 
APÉNDICE I. Etapas del Programa de Implementación para el carpintero gigante (Campephilus magellanicus) como especie carismática (PI-Carpintero) de la Reserva de Biosfera Cabo de Hornos.

\begin{tabular}{|c|c|}
\hline Etapa & Actividades fundamentales \\
\hline $\begin{array}{l}\text { Etapa 1: Definición de } \\
\text { problemas prioritarios. }\end{array}$ & $\begin{array}{l}\text { 1) C. magellanicus es una especie en categoría de conservación Vulnerable (Glade 1993), } \\
\text { 2) su hábitat está sujeto a presiones económicas crecientes, } \\
\text { 3) los bosques tienen manejo y control limitado y } \\
\text { 4) la introducción de especies depredadoras exóticas invasoras (Rozzi et al. 2006a). }\end{array}$ \\
\hline $\begin{array}{l}\text { Etapa 2: Identificación } \\
\text { y evaluación de la } \\
\text { población objetivo, } \\
\text { de los recursos } \\
\text { disponibles y del } \\
\text { escenario. }\end{array}$ & $\begin{array}{l}\text { Aumento del conocimiento de la especie y de su hábitat y conocimiento de sus interacciones ecoló- } \\
\text { gicas a través del trabajo directo del equipo del PI-Carpintero con todos los sectores de la población } \\
\text { de Puerto Williams. } \\
\text { Incentivo del interés y entusiasmo como orgullo local como una especie bella y rara y su asociación } \\
\text { a ventajas económicas a través del fomento del turismo en la localidad. } \\
\text { El trabajo con medios de comunicación reforzó la imagen del carpintero gigante como símbolo de la } \\
\text { Reserva de Biosfera Cabo de Hornos. }\end{array}$ \\
\hline $\begin{array}{l}\text { Etapa 3: Desarrollo de } \\
\text { interacciones positivas } \\
\text { con los participantes. }\end{array}$ & $\begin{array}{l}\text { Trabajo con las entidades públicas y líderes locales: Gobernador de la Provincia Antártica Chilena, } \\
\text { Alcalde de la I. Municipalidad Cabo de Hornos, Comandantes de la Armada de Chile, JUNJI, Cámara } \\
\text { de Turismo, Director del Liceo Donald McIntyre, agrupaciones comunales, otros. }\end{array}$ \\
\hline $\begin{array}{l}\text { Etapa 4: Selección } \\
\text { de los métodos. }\end{array}$ & $\begin{array}{l}\text { Selección, planificación y ejecución sistemática de actividades relacionadas entre sí (talleres, charlas, } \\
\text { entrega de regalos, concursos, campaña ambiental, trabajo de terreno, celebraciones, etc.) enfocadas } \\
\text { hacia la población escolar. } \\
\text { Desarrollo del Taller de Historia Natural con niños del Liceo. } \\
\text { Participación en la Semana de la Ciencia Nacional Chilena (EXPLORA-CONICYT). }\end{array}$ \\
\hline $\begin{array}{l}\text { Etapa 5: } \\
\text { Implementación } \\
\text { de actividades. }\end{array}$ & $\begin{array}{l}\text { Demostración de los atributos de la especie para aumentar la conciencia de su conservación por la } \\
\text { entrega de conocimiento y de materiales. Creación de herramientas para una actividad sustentable } \\
\text { a través del contacto directo con la comunidad. } \\
\text { Las actividades desarrolladas con la comunidad local de Puerto Williams entre el } 2005 \text { y abril } 2007 \\
\text { fueron: } \\
\text { - Talleres de Educación Ambiental dirigidos a niños y profesores a través de sesiones expositivas, } \\
\text { juegos y salidas a terreno; } \\
\text { - Talleres de Ecoturismo con sesiones expositivas y actividades en terreno; } \\
\text { - Exposición "El Valor de la Biodiversidad Austral" en el liceo local con diseño y producción del } \\
\text { - material de difusión correspondiente; } \\
\text { - Presentaciones públicas de una obra de teatro y una pieza de títeres en vivo realizados por los niños } \\
\text { - Acl Taller Omora; } \\
\text { - Concuridades de Avistamiento de los carpinteros gigantes en el Parque Omora; } \\
\text { - Campaña Ambiental en coordinación con la Municipalidad del Cabo de Hornos con el carpintero } \\
\text { - Gigante como símbolo; } \\
\text { - Pelebración del "Día de la Tierra" con entrega de regalos con la imagen del carpintero gigante; } \\
\text { - Publicación y entrega de materiales de difusión en Internet en el sitio oficial de C. magellanicus en } \\
\text { - Participación del Taller de Historia Natural en eventos científicos nacionales escolares auspiciados } \\
\text { por CONICYT: Feria Científica Regional, Semana de la Ciencia. Obtención del Primer Premio } \\
\text { 2007; } \\
\text { - Elaboración de bordados con fauna nativa por parte de artesanas locales; } \\
\text { - Visitas Guiadas en el Parque Omora dirigidas a públicos distintos: escolares, profesores, operadores } \\
\text { turísticos, estudiantes graduados, voluntarios, políticos, autoridades de Gobierno locales, regionales, } \\
\text { nacionales e internacionales, representantes de la Armada, científicos, turistas, periodistas, visitantes } \\
\text { distinguidos; } \\
\text { - Inclusión de Campephilus magellanicus en el Plan de Acción Nacional para la Conservación de la } \\
\text { Biodiversidad-Región de Magallanes y Antártica Chilena de CONAMA Regional. }\end{array}$ \\
\hline
\end{tabular}




\begin{tabular}{|c|c|}
\hline $\begin{array}{l}\text { Etapa 5: } \\
\text { Implementación } \\
\text { de actividades. }\end{array}$ & $\begin{array}{l}\text { Los materiales producidos por el PI-Carpintero incluyeron: } \\
\text { - Noticias de prensa y entrevistas en la radio y televisión local; } \\
\text { - Capítulos en dos programas de la Televisión Nacional de Chile; } \\
\text { - Programa completo sobre la conservación de C. magellanicus para televisión por cable; } \\
\text { - DVD con una pieza de títeres; } \\
\text { - Posters de los trabajos de investigación presentados en la Feria Científica Regional por alumnos del } \\
\text { Taller Omora; } \\
\text { - Posters presentados a distintas escalas (local, regional, nacional e internacional); } \\
\text { - Capítulos en libros; } \\
\text { - Cuatro series diferentes de postales; } \\
\text { - CD con charlas para ser presentadas en talleres de ecoturismo y de educación; } \\
\text { - Bolsas de tela con dibujos del carpintero gigante; } \\
\text { - Insignias y tarjetas con mensajes de conservación; } \\
\text { - Cuadros con fotografías del carpintero gigante con textos alusivos a su conservación como regalo } \\
\text { - del programa a líderes comunales y dueños de locales comerciales que los exhiben en sus locales; } \\
\text { - de Magallanes; } \\
\text { - Diseño preliminar del logotipo de la Reserva de Biosfera Cabo de Hornos que incluye a C. mage- } \\
\text { - Inclusión del carpintero gigante en el afiche de la CONAMA producido en el marco del Plan de } \\
\text { Acción Nacional para la Conservación de la Biodiversidad. }\end{array}$ \\
\hline Etapa 6: Evaluación. & $\begin{array}{l}\text { La imagen del carpintero gigante se encuentra hoy en el discurso público local y son numerosos los } \\
\text { casos donde los representantes del Gobierno han hecho referencias públicas a la importancia de esta } \\
\text { especie para la localidad. } \\
\text { Dos campañas ambientales en curso de la I. Municipalidad Comuna Cabo de Hornos y de la Armada } \\
\text { de Chile, tienen la imagen del carpintero gigante como símbolo de un ambiente limpio y natural. } \\
\text { La empatía hacia la especie surgió de reuniones entre el Comité Científico de la RBCH y la Munici- } \\
\text { palidad, donde se ha conversado reiteradamente sobre la importancia de C. magellanicus y se han } \\
\text { planteado ideas que han podido concretarse en conjunto. } \\
\text { A nivel regional, un logro significativo del programa ha sido la inclusión de C. magellanicus en el } \\
\text { Plan de Acción Nacional para la Conservación de la Biodiversidad-Región de Magallanes y Antártica } \\
\text { Chilena de CONAMA regional. } \\
\text { A nivel local, ha aumentado el interés del interés público en la especie evidenciado a través de los } \\
\text { siguientes indicadores: } \\
\text { - Fotografía de la especie publicada por SERNATUR regional para promocionar la visita turística al } \\
\text { Cabo de Hornos en una revista internacional -el National Geographic Magazine-donde el carpintero } \\
\text { gigante representa a fauna terrestre de la región, y en un folleto bilingüe; } \\
\text { - Pinturas de C. magellanicus de artistas de Puerto Williams, exhibidas en las dependencias de la } \\
\text { Municipalidad del Cabo de Hornos y hostales, con grupos familiares de carpinteros (macho, hembra } \\
\text { y polluelos) que destacan en cuanto respetan características biológicas de la especie, como coloración } \\
\text { - Materiales de difusión (folletos) turística local y regional publicada por personas de la comunidad } \\
\text { local que incluyen fotos del carpintero; } \\
\text { - Interés por parte de comerciantes locales por exponer fotografías de C. magellanicus y solicitud } \\
\text { para la venta de material de difusión (como postales) en sus tiendas; } \\
\text { - Interés demostrado por las empresas regionales, como la empresa EDELMAG que imprimió calen- } \\
\text { darios } 2007 \text { con fotografías del ave. } \\
\text { - Adopción de la imagen del carpintero gigante como símbolo para campañas ambientales de la I. } \\
\text { Municipalidad de Cabo de Hornos y de la Base Naval Beagle de la Armada de Chile. }\end{array}$ \\
\hline Etapa 7: Reciclaje. & $\begin{array}{l}\text { Aunque esta etapa está en curso, instituciones como la Armada de Chile han decidido replicar algunas } \\
\text { iniciativas ejecutadas por nuestro programa. Los materiales educativos producidos en este programa } \\
\text { pueden ser ocupados por distintas generaciones de estudiantes, jardín infantil, profesores, operadores } \\
\text { turísticos, etc. De esta manera, la conservación de esta especie podría reflejarse hacia el norte del } \\
\text { país como un ejemplo nacional. } \\
\text { Una expresión notable de continuidad se encuentra en la imagen de postales de la Reserva de Biosfera } \\
\text { Cabo de Hornos, y tanto la imagen de C. magellanicus como elementos de su hábitat, se encuentran } \\
\text { en el diseño preliminar del logotipo oficial de la Reserva de Biosfera Cabo de Hornos. }\end{array}$ \\
\hline
\end{tabular}

